KOsnเn: Jurnal IImu Kesehatan Vol. 9 No.1 Mei 2021

\title{
GAMBARAN PERILAKU HIDUP BERSIH DAN SEHAT (PHBS) PADA TATANAN KELUARGA DI DESA WANGUNGJAYA CIANJUR
}

\author{
Puspita Hanggit Lestari, Martini , Ardiansyah \\ STIKes RS HUSADA, Jakarta Pusat, DKI Jakarta, Indonesia
}

\begin{abstract}
Abstrak
Latar belakang : pelaksanaan perilaku bersih dan sehat pada tatanan keluarga bertujuan memberdayakan anggota keluarga untuk tahu, mau dan mampu menjalankan perilaku kehidupan yang bersih dan sehat. Perilaku tidak sehat dapat menjadi penyebab munculnya penyakit atau masalah kesehatan seperti diare dan batuk pilek.

Tujuan : penelitian ini untuk memperoleh gambaran perilaku hidup bersih dan sehat masyarakat di Desa Wangunjaya pada komponen pengetahuan, sikap dan tindakan pelaksanaan PHBS.

Subjek dan metode : populasi penelitian ini adalah seluruh kepala keluarga di Desa Wangunjaya. Sampel penelitian ini berjumlah 206 orang. Teknik pengambilan sampel yang digunakan dalam penelitian ini adalah simple random sampling. Analisa data dilakukan dengan melakukan analisis unuvariat dengan penyajian data deskriptif analitik dan analisis bivariat dengan Uji Chi Square dengan melihat ukuran OR (Odds Ratio) untuk mengetahui adanya perbedaan proporsi variabel yang diteliti untuk melihat hubungan antara variabel.

Hasil : penelitian mendapatkan hasil varibel pengetahuan $(58,3 \%)$, sikap $(51,5 \%)$ dan pelaksanaan PHBS $(41,7 \%)$ dalam kategori kurang. Pengetahuan memiliki hubungan dengan tindakan pelaksanan PHBS $(p$ value $=0,000)$. Variabel sikap memiliki hubungan dengan tindakan pelaksanan PHBS ( $p$ value $=0,006)$.

Kesimpulan : pengetahuan yang baik memiliki peluang 3,569 kali untuk tindakan PHBS yang baik. Sikap yang baik memiliki peluang 2,288 kali untuk tindakan PHBS yang baik.
\end{abstract}

Kata kunci : pengetahuan, PHBS, promosi kesehatan, sikap

\section{OVERVIEW OF CLEAN AND HEALTHY LIFESTYLE BEHAVIOR IN FAMILY ORDER IN WANGUNGJAYA VILLAGE CIANJUR}

\author{
Puspita Hanggit Lestari, Martini, Ardiansyah
}

\begin{abstract}
Background : the implementation of clean and healthy behavior in the family scope aims to empower family members to know, want and be able to carry out clean and healthy life behaviors. Unhealthy behavior can cause illness or health problems such as diarrhea and cold coughs.

The aim of the study : to obtain an overview of the clean and healthy behavior of the community in Wangunjaya Village on the components of knowledge, attitudes and actions in implementing of clean and healthy behavior.

Subjects and methods : the population of this study were all heads of families in Wangunjaya Village, Cianjur. The sample of this research is 206 people. The sampling technique used in this study was simple random sampling. Data analysis was carried out by univariate analysis by presenting descriptive analytic data and bivariate analysis with the Chi Square Test by looking at the OR (Odds Ratio) size to determine the difference in the proportion of the variables studied to see the relationship between the variables.

Results : the study found that the variable knowledge (58.3\%), attitudes (51.5\%) and the implementation of PHBS (41.7\%) were in the low category. Knowledge has a relationship with the implementation of clean and healthy behavior ( $p$ value $=0,000$ ). Attitude variable has a relationship with the action of implementing clean and healthy behavior ( $p$ value $=$ 0.006).
\end{abstract}


Conclusion : good knowledge has a 3,569 times chance for good PHBS action. A good attitude has 2,288 times the chance for good PHBS action.

Keywords: attitude, clean and healthy behavior, health promotion, knowledge

Korespondensi: Puspita Hanggit Lestari. STIKes RS Husada. Email : puspita@stikesrshusada.ac.id

\section{LATAR BELAKANG}

$\begin{array}{lll}\text { Pelaksaan perilaku hidup } & \text { dan sehat dapat } \\ \text { bersih dan }\end{array}$ mempengaruhi derajat kesehatan sebuah negara. Pemerintah Indonesia telah meluncurkan program pembinaan PHBS perilaku hidup bersih dan sehat sejak tahun 1996, tetapi keberhasilannya masih jauh dari harapan. Riset Kesehatan Dasar (Riskesdas) Tahun 2007 mengungkap bahwa rumah tangga di Indonesia yang mempraktekkan PHBS baru mencapai $38,7 \%$ (Kemenkes RI, 2011). Persentase rumah tangga yang mempraktikkan PHBS tahun 2013 meningkat menjadi $55,6 \%$. Namun pencapaian tahun 2013 tersebut tampak masih jauh dari target yang ditetapkan pada rencana strategis kementrian kesehatan tahun 2010-2014 sebesar 70\% (Kemenkes RI, 2011). Kementrian Kesehatan RI (2016) menjelaskan salah satu tatanan PHBS yang utama adalah PHBS rumah tangga yang bertujuan memberdayakan anggota sebuah rumah tangga untuk tahu, mau dan mampu menjalankan perilaku kehidupan yang bersih dan sehat serta memiliki peran yang aktif pada gerakan di tingkat masyarakat. Terdapat beberapa indikator PHBS pada tingkatan rumah tangga yang dapat dijadikan acuan untuk mengenali keberhasilan dari praktik Perilaku Hidup Bersih dan Sehat pada tingkatan rumah tangga. PHBS pada tingkatan rumah tangga yaitu persalinan yang ditolong oleh tenaga kesehatan, pemberian ASI eksklusif, menimbang bayi dan balita secara berkala, cuci tangan dengan sabun dan air bersih, menggunakan air bersih, menggunakan jamban sehat, memberantas jentik nyamuk, konsumsi buah dan sayur, melakukan aktivitas fisik setiap hari, dan tidak merokok di dalam rumah.

Beberapa indikator dalam PHBS tatanan keluarga mengalami peningkatan berdasarkan hasil Riskesdas 2018 (Kemenkes RI, 2018). Indikator tersebut antara lain perilaku cuci tangan makin baik meningkat dari $47 \%$ pada Riskesdas 2013 menjadi 49,8\% pada Riskesdas, 2018. Perilaku buang air besar di jamban semakin baik meningkat dari $82,6 \%$ pada Riskesdas 2013 menjadi 88,2\% pada Riskesdas 2018. Hasil Riskesdas 2013 didapatkan bahwa persentase pernerapan PHBS di perkotaan $42,3 \%$ sedangkan di pedesaan lebih rendah yaitu $22,9 \%$. Penerapan PHBS di wilayah pedesaan yang rendah dapat memunculkan penyakit atau masalah kesehatan. Pelaksanaan PHBS yang buruk berpengaruh pada kejadian diare dan demam berdarah (Anggraini, Dian Aviyanti, \& Saputri, 2014 ; Raksanagara \& Raksanagara, 2015). Semakin tinggi nilai PHBS makan semakin rendah kejadian penyakit diare, demam berdarah dan angka bebas larva (Raksanagara \& Raksanagara, 2015). Pelaksanaan indikator PHBS seperti pemberian ASI eksklusif, status gizi, perilaku cuci tangan, perilaku merokok berhubungan dengan kejadian ISPA berulang (Aldila, 2015). 
Desa Wangunjaya merupakan salah satu desa yang berada di Kabupaten Cianjur Kecamatan Cugenang, dengan luas wilayah $707.195 \mathrm{Ha}$ dan berada di dataran tinggi dengan ketinggian kurang lebih 6,63 meter di atas permukaan laut (mdpl). Sebagian lebih wilayah Desa Wangunjaya merupakan lahan pertanian dan perkebunan. Kondisi jalan Desa Wangunjaya masih banyak bebatuan dan tanah, serta akses transportasi yang masih minim bias menjadi salah satu faktor yang membuat tingkat kesejahteraan social banyak yang kurang mampu.

Studi pendahuluan yang dilakukan terkait masalah kesehatan yang dialami masyarakat di Desa Wangunjaya dalam 1 bulan terakhir pada tahun 2019 didapatkan data 29 warga mengalami batuk pilek dan 4 warga mengalami diare. Perilaku tidak sehat dapat menjadi penyebab munculnya penyakit atau masalah kesehatan (Glanz, Rimer \& Viswanath, 2015). Penerapan program PHBS bertujuan agar dapat meningkatkan kesadaran masyarakat untuk mau menjalankan hidup bersih dan sehat. Manfaat dari pelaksanaan PHBS adalah agar masyarakat bisa mencegah dan menanggulangi masalah kesehatan (Kemenkes RI, 2016).

\section{TUJUAN PENELITIAN}

Mengetahui gambaran perilaku hidup bersih dan sehat masyarakat di Desa Wangunjaya. Pelaksanaan PHBS tatanan rumah tangga akan diidentifikasi sesuai indikator PHBS pada tingkatan rumah tangga yaitu persalinan yang ditolong oleh tenaga kesehatan, pemberian ASI eksklusif, menimbang bayi dan balita secara berkala, cuci tangan dengan sabun dan air bersih, menggunakan air bersih, menggunakan jamban sehat, memberantas jentik nyamuk, konsumsi buah dan sayur, melakukan aktivitas fisik setiap hari, dan tidak merokok di dalam rumah. Hasil dari penelitian ini dapat menjadi landasan pengembangan program promosi kesehatan dan sumber daya bagi Puskesmas Cugenang untuk melakukan penyuluhan dan pemantauan PHBS keluarga secara rutin.

\section{METODE}

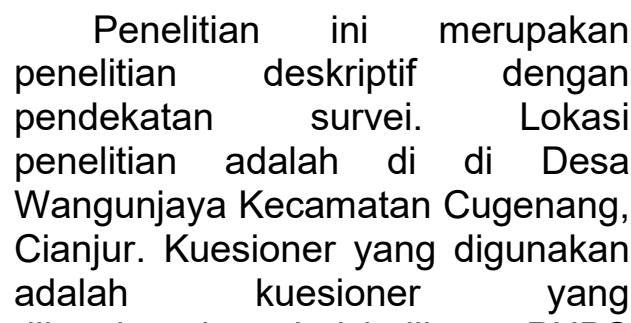
dikembangkan dari indikator PHBS (Kemenkes RI, 2011). Analisis data berupa analisis univariat dengan penyajian data deskripif analitik pada variabel karekteristik responden dan pelaksanaan indikator PHBS dan analisis bivariat untuk melihat adanya perbedaan proporsi variabel yang diteliti untuk melihat hubungan antara variabel.

\section{POPULASI, SAMPEL DAN TEKNIK SAMPLING}

Populasi penelitian ini adalah seluruh kepala keluarga di Desa Wangunjaya. Sampel penelitian ini berjumlah 206 orang. Teknik pengambilan sampel yang digunakan dalam penelitian ini adalah simple random sampling. 
HASIL PENELITIAN

Hasil penelitian ini adalah berikut:

Tabel 1.

Karakteristik Responden

Desa Wangunjaya $(n=206)$

\begin{tabular}{lcc}
\hline \multicolumn{1}{c}{ Variabel } & $\mathrm{n}$ & $\%$ \\
\hline Usia & & \\
Remaja 18 tahun & 7 & 53 \\
Dewasa $19-59$ & 156 & 4 \\
tahun & & \\
Lansia $\geq 60$ tahun & 43 & 21 \\
Usia (mean \pm SD) & 44,62 & \\
& \pm 16.291 & \\
Jenis Kelamin & & \\
Laki-laki & 60 & 29,1 \\
Perempuan & 146 & 70,9 \\
Pedidikan Terakhir & & \\
SD & 170 & 82,5 \\
SMP & 19 & 9,2 \\
SMA & 15 & 7,3 \\
Perguran Tinggi & 2 & 1 \\
\hline
\end{tabular}

Umur responden mayoritas dalam usia dewasa 19 - 59 tahun sebanyak 156 orang(53\%) dengan usia rata-rata 44,62 tahun. Jenis kelamin responden mayoritas adalah perempuan sebanyak 146 orang $\quad(70,9 \%)$. Mayoritas responden memiliki pendidikan terakhir SD yaitu 170 orang $(82,5 \%)$.

Tabel 2.

Karakteristik Responden

\begin{tabular}{lcc}
\multicolumn{3}{c}{ Desa Wangunjaya $(\mathrm{n}=206)$} \\
\hline \multicolumn{1}{c}{ Variabel } & $\mathrm{n}$ & $\%$ \\
\hline $\begin{array}{l}\text { Pengetahuan } \\
\text { Kurang }\end{array}$ & 120 & 58,3 \\
$\begin{array}{l}\text { Baik } \\
\text { Sikap }\end{array}$ & 86 & 41,7 \\
Kurang & 106 & 51,5 \\
Baik & 100 & 48,5 \\
Tindakan & & \\
Kurang & 118 & 57,3 \\
Baik & 88 & 42,7 \\
\hline
\end{tabular}

Penelitian mendapatkan hasil sebanyak 120 responden (58,3\%) memiliki pengetahuan dengan kategori kurang, sedangkan sebanyak 86 responden $(41,7 \%)$ memiliki pengetahuan dalam kategori baik. Penelitian terhadap sikap PHBS didapatkan 106 rersponden $(51,5 \%)$ memiliki sikap dalam kategori kurang terkait PHBS sebanyak 100 responden $(48,5 \%)$ memiliki sikap dalam kategori baik. Penelitian terkait tindakan pelaksanaan PHBS didapatkan 118 responden $(57,3 \%) \quad$ memiliki tindakan dalam kategori kurang, sedangkan 88 responden $(42,7 \%)$ terdapat dalam kategori baik.

\section{PEMBAHASAN}

\begin{tabular}{lcr}
\multicolumn{2}{c}{ Perilaku Hidup } & Bersih dan \\
Sehat (PHBS) & merupakan \\
sekumpulan & perilaku & yang \\
menjadikan & seorang & invidu, \\
keluarga, & kelompok & atau \\
masyarakat & mampu & menolong
\end{tabular} dirinya sendiri dalam kesehatan dan berperan aktif dalam mewujudkkan kesehatan masyarakat (Kemenkes RI, 2011). Perilaku kesehatan dilakukan seseorang agar terhindar dari penyakit dan meningkatkan kesehatannya. Perilaku kesehatan, terkadang disebut perilaku yang berhubungan dengan kesehatan, adalah tindakan yang diambil oleh individu yang berpengaruh pada kesehatan atau kematian (Short \& Mollborn, 2015).

Perilaku kesehatan sangat dipengaruhi oleh lingkungan fisik, ekonomi, hukum, dan sosial yang menentukan kehidupan sehari-hari masyarakat (Diclemente, 2018). Perilaku individu dipengaruhi oleh lingkungan dan saling memperngaruhi. Selain itu, perilaku individu berkaitan dengan faktorfaktor pengetahuan dan sikap individu (Kemenkes RI, 2011).

Pengetahuan merupakan Informasi dan keterampilan yang diperoleh melalui pengalaman, observasi, atau pendidikan (Diclemente, 2018). Penelitian terkait pengetahuan PHBS di berbagai tempat di Indonesia menunjukkan hasil yang beragam. 
Penelitian ini mendapatkan hasil mayoritas responden memilki pengetahuan dengan kategori kurang. Penelitian lain terkait pengetahuan PHBS juga mendapatkan gambaran terdapat masyarakat dengan kategori pengetahuan yang kurang terkait PHBS (Miswanto, Yuniar \& Bahar, 2015; Yuliandari \& Herya, 2016).

Pengetahuan yang dimiliki masyarakat rendah terkait hal ini mungkin berhubungan dengan latar belakang pendidikan dari responden. Faktor yang mempengaruhi pengetahuan menurut Budiman dan Riyanto (2013) antara lain pendidikan, informasi tau media masa, sosial budaya dan ekonomi, dan lingkungan. Seseorang yang memiliki tingkat pendidikan tinggi maka akan cepat menerima dan memahami suatu informasi sehingga pengetahuan yang dimiliki juga semakin tinggi. Informasi mempengaruhi pengetahuan seseorang jika sering mendapatkan informasi tentang suatu pembelajaran maka akan pengetahuan dan wawasan individu akan meningkat.

$$
\text { Tradisi atau budaya }
$$

seseorang yang dilakukan tanpa penalaran baik atau buruk berpengaruh terhadap pengetahuan individu.Status ekonomi juga akan menentukan tersedianya fasilitas yang dibutuhkan untuk kegiatan tertentu. Seseorang yang dalam kondisi sosial budayanya kurang baik maka pengetahuannya akan kurang baik. Status ekonomi seseorang mempengaruhi tingkat pengetahuan karena seseorang yang memiliki status ekonomi dibawah rata-rata maka seseorang tersebut akan sulit untuk meningkatkan pengetahuan. Lingkungan mempengaruhi proses masuknya pengetahuan kedalam individu karena adanya interaksi timbal balik. Lingkungan yang baik akan pengetahuan yang didapatkan akan baik tapi jika lingkungan kurang baik maka pengetahuan yang didapat juga akan kurang baik. Jika seseorang berada di sekitar orang yang berpendidikan maka pengetahuan yang dimiliki seseorang akan berbeda dengan orang yang berada di sekitar orang pengangguran dan tidak berpendidikan.

Sikap terhadap perilaku kesehatan adalah konstruksi utama baik dalam teori tindakan beralasan dan teori perilaku terencana, yang terdiri dari evaluasi kolektif seseorang terhadap nilai atau nilai keseluruhan dari melakukan perilaku kesehatan tertentu (Diclemente, 2018). Penelitian terhadap sikap terhadap PHBS ini memperoleh $51,5 \%$ memiliki sikap dalam kategori kurang sedangkan $48,5 \%$ dalam kategori baik. Hal ini diisebabkan karena sebagian responden tidak setuju pada pernyataan untuk tidak merokok di dalam rumah dan persalinan yang ditolong dengan nakes. Hasil penelitian ini sama dengan hasil yang diperoleh oleh Miswanto, Yuniar \& Bahar (2015) yang mendapatkan hasil penelitian lebih banyak responden memiliki sikap buruk tentang PHBS yaitu berjumlah 65 orang $(70,7 \%)$.

Sikap adalah perasaan, kecenderungan, atau seperangkat keyakinan yang relatif konstan yang diarahkan pada suatu objek, orang, atau situasi, biasanya dalam menilai sesuatu sebagai baik atau buruk, positif atau negatif (Stanhope \& Lancaster, 2016). Ada perbedaan yang konsisten antara cara penduduk pedesaan dan nonpedesaan memandang kesehatan (Nies \& Mc. Ewen, 2019). Sikap penduduk pedesaan pada umumnya menekankan pada aspek "melakukan" kesehatan dalam melaksanakan fungsi dan melakukan aktivitas yang mendasar 
hanya hal-hal penting dalam kehidupan sehari-hari.

Faktor yang mempengaruhi sikap terhadap kesehatan menurut Azwar (2011) antara lain pengalaman pribadi, pengaruh orang lain yang dianggap penting, pengaruh kebudayaan, media masa, dan faktor emosional. Pengalaman pribadi dan pengaruh kebudayaan erat dengan pembetukan perilaku kesehatan yang tidak sehat seperti merokok. Merokok tidak dianggap menjadi perilaku yang mengancam kesehatan dan menjadi kebiaasaan yang dilakukan oleh masyarakat.

Penelitian terkait tindakan pelaksanaan PHBS didapatkan $42,7 \%$ terdapat dalam kategori baik. Penerapan PHBS baik berkaitan dengan sudah baiknya pelaksanaan pemberian ASI eksklusif, penggunaan air bersih untuk rumah tangga penggunaan jamban, rutinitas melakukan aktivitas fisik setiap hari. Namun, angka pelaksanaan PHBS ini lebih rendah dibandingkan angka persentase nasional rumah tangga yang mempraktikkan PHBS tahun 2013 sebesar 55,6\% (Kemenkes RI, 2015).

Faktor yang diketahui berhubungan dengan tindakan pelaksanaan PHBS pada penelitian ini adalah pengetahuan dan sikap. Pengetahuan dan sikap memiliki hubungan yang signifikan dengan Tindakan PHBS (Saini \& Aminah, 2015; Anggareni, Suniyadewi, \& Devhy, 2018). Namun hasil ini tidak sejalan dengan penelitian Pratiwi, et al (2018) dan Putri, et al (2019) yang memperoleh hasil tidak ada hubungan antara pengetahuan dan sikap dengan tindakan PHBS. Perbedaan ini mungkin terjadi karena ada nya perberdaan karakteristik responden dan wilayah penelitian.

$\begin{array}{clc}\text { Faktor } & \text { lain } & \text { yang } \\ \text { mempengaruhi } & \text { PHBS } & \text { selain }\end{array}$

pengetahuan dan sikap adalahmedia informasi yang masih kurang, terbatasnya sarana pelayanan kesehatan dan jarak yang cukup jauh masyarakat dengan pelayanan kesehatan primer puskesmas (Manurung, 2019). Wilayah penelitian juga memiliki jarak yang jauh dengan puskesmas. Informasi kesehatan tekait dengan PHBS juga terbatas didapatkan oleh warga.

Kesehatan dan perilaku kesehatan seseorang mencerminkan kondisi fisik yang dikombinasikan dengan kumpulan pengalaman dan keadaan yang telah terungkap dari waktu ke waktu, dalam konteks sosial dan fisik yang berbeda. Perspektif ini, perpaduan antara sosiologi medis, demografi sosial, dan epidemiologi sosial, menekankan pada lingkungan sosial kesehatan, atau yang lebih dikenal sebagai determinan sosial kesehatan (Short \& Mollborn, 2015).

Perilaku tidak sehat menjadi penyebab kematian yang tidak proporsional di negara-negara di seluruh dunia. Dan munculnya penyakit tidak menular secara global merupakan ancaman utama bagi kondisi di dunia karena dapat mendorong banyak orang di bawah garis kemiskinan (Glanz, Rimer \& Viswanath, 2015). Peranan tenaga kesehatan untuk meningkatkan peran keluarga dalam pelaksanaan perilaku hidup bersih dan sehat diperlukan untuk mencegah munculnya berbagai penyakit. Promosi kesehatan perlu dilaksanakan untuk merubah perilaku masyarakat agar dapat menerapkan perilaku hidup sehat.

Promosi kesehatan merupakan upaya perubahan atau perbaikan perilaku di bidang kesehaan disertai dengan upaya yang mempengaruhi lingkungan (Kholid, 2018). Promosi kesehatan juga berarti upaya yang bersifat promotif (peningkatan), 
upaya preventif (pencegahan), kuratif (pengobatan) dan rehabilitatif (pemulihan) dalam rangkaian upaya kesehatan yang komprehensif. Promosi kesehatan dapat berupa penyuluhan atau pendidikan kesehatan agar dapat meningkatkan pengetahuan dan perilaku masyarakat.

\section{KESIMPULAN}

Penelitian ini memperoleh gambaran pelaksanaan PHBS pada tatanan keluarga di wilayah pedesaan. Pengetahuan, Sikap dan Tindakan PHBS pada responden mayoritas berada pada kategori kurang. Terdapat hubungan antara pengetahuan dan sikap dengan pelaksanaan PHBS. Pengetahuan yang baik memilki peluang 3,569 kali untuk tindakan PHBS yang baik. Sikap yang baik memiliki peluang 2,288 kali untuk tindakan PHBS yang baik. Perilaku tidak sehat berpotensi memunculkan penyakit dan menyebabkan kematian.

\section{SARAN}

Hasil dari penelitian ini dapat digunakan dalam menentukan program promosi kesehatan yang sesuai untuk meningkatkan program PHBS. Program promosi kesehatan terkait PHBS dapat dilaksanakan dengan mengembangkan kebijakan pembangunan kesehatan, berwawasan masyararakat, memberdayakan meningkatkan keterampilan keluarga terhadap PHBS, mendekatkan pelayanan kesehatan dan pendidikan kesehatan agar masyarakat lebih mudah mendapatkan informasi kesehatan.

\section{DAFTAR PUSTAKA}

Aldila,T,Y.(2015).Analisis faktor perilaku hidup bersih dan sehat (phbs) dengan kejadian penyakit ispa berulang pada balita di wilayah kerja puskesmas pekalongan selatan kota pekalongan. Under Graduates thesis, Universitas Negeri Semarang.

Anggareni, Suniyadewi, \& Devhy. (2018). Hubungan pengetahuan dan sikap keluarga dengan penerapan hidup bersih dan sehat pada tatanan rumah tangga di desa payangan wilayah kerja puskesmas marga i tabanan. Bali Medika Jurnal Vol 5 No 2 December 2018 diakses dari

https://balimedikajurnal.com/inde x.php/bmj/article/view/31.

Anggraini,M.T, Aviyanti,D\& Saputri, D. M. (2014). PHBS yang Buruk Meningkatkan Kejadian Diare. Jurnal Kedokteran Muhamadiyah Vol 3 No. 1 diakses dari https://jurnal.unimus.ac.id/index.p hp/kedokteran/article/view/2576.

Azwar, S. (2011). Sikap dan Perilaku Dalam: Sikap Manusia Teori dan Pengukurannya. Yogyakarta: Pustaka Pelajar.

Budiman \& Riyanto. 2013. Kuesioner Pengetahuan dan Sikap Dalam PenelitianKesehatan. Jakarta: Salemba Medika.

Glanz, K., Rimer, B. K., \& Viswanath, K. "V." (Eds.). (2015). Health behavior: Theory, research, and practice (5th ed.). JosseyBass/Wiley. American Psychological Assocation. Diakses dari https://psycnet.apa.org/record/20 15-35837-000.

Kementrian Kesehatan RI. (2018). Hasil utama riset kesehatan dasar 2018. Badan Penelitian dan Pengembangan Kesehatan.

Kementrian Kesehatan RI.(2011). Pedoman Pembinaan Perilaku Hidup Bersih dan Sehat (PHBS). Jakarta: Kementrian Kesehatan RI.

Kementrian Kesehatan RI.(2016). PHBS : Gerakan PHBS Sebagai Langkah Awal Menuju Peningkatan Kualitas Kesehatan Masyarakat. Diakses dari https://promkes.kemkes.go.id/ph bs. 
Kholid,A. (2018).PromosiKesehatan : dengan pendekatan teori perilaku, media dan aplikasinya, Jakarta : Rajawali Pers.

Manurung, N.(2019). Faktor-Faktor Yang Mempengaruhi Keluarga Dalam Penerapan Perilaku HidupBersih Dan Sehat Di Desa Pematang Lalang. Jurnal IImiah Keperawatan Imelda. Diakses dari

https://jurnal.uimedan.ac.id/index .php/JURNALKEPERAWATAN/a rticle/view/300.

Miswanto, Yuniar, N\& Bahar,H.(2015). Gambaran perilaku hidup bersih dan sehat (phbs) pada masyarakat di wilayah kerja puskesmas welala kecamatan ladongi kabupaten kolaka timur tahun 2015. Jurnal IImiah Mahasiswa Kesehatan Masyarakat Vol 1 No 3. Diakses dari

http://ojs.uho.ac.id/index.php/JIM KESMAS/article/view/1321.

Nies, M.A\& Mc. Ewen, M. (2019) . Community/public health nursing: promoting the health of populations seventh edition. Missouri: Elsevier.

Pratiwi, et al,. (2018). Correlation of Knowledge With The Attitude of Head Family About Clean And Healthy Behaviour (Phbs) In Cilembang Cihideung Tasikmalaya. Journal of Midwifery Vol 3, No 2 (2018).DOI:

https://doi.org/10.25077/jom.3.2. 37-44.2018 diakses dari http://jom.fk.unand.ac.id/index.ph p/jom/article/view/78.

Putri, R, M, Rosidana, Y., \& Nisa, A, C. (2019). Application of Clean and Healthy Living Behavior (PHBS) From The Household Knowledge and Attitude Study. 3 . Vol. 3 No. 1 (2019): Journal Of Nursing Practice . diakses dari https://thejnp.org/index.php/jnp/ar ticle/view/64.
Raksanagara, Ar\& Raksanagara, Ah.(2015). Perilaku hidup bersih dan sehat sebagai determinan kesehatan yang penting pada tatanan rumah tangga di kota bandung. Jurnal Sistem Kesehatan Vol 1, No 1. Diakses dari

http://jurnal.unpad.ac.id/jsk_ikm/a rticle/view/10340.

Saini, S\& Aminah,S.(2015). Pengetahuan dan sikap keluarga dalam pelaksanaan perilaku hidup bersih dan sehat di wilayah kerja puskesmas sombaopu gowa. Jurnal Media Keperawatan Vol 9, No. 1. (2018) diakses dari http://journal.poltekkesmks.ac.id/ojs2/index.php/mediak eperawatan/article/view/109.

Short, S. E.\& Mollborn, S. (2015). Social Determinants and Health Behaviors: Conceptual Frames and Empirical Advances. Curr Opin Psychol. Author manuscript; available in PMC 2016 Oct 1. Published in final edited form as: Curr Opin Psychol. 2015 Oct; 5: 78-84.doi: 10.1016/j.copsyc.2015.05.002.

Stanhope, \& Lancaster. (2016). Community and public health nursing. St.Louis:Mosby-Year Book, Inc.

Yuliandari, D. W. \& Herya, N. (2016). Pengaruh pengetahuan dan sosial ekonomi keluarga terhadap penerapan perilaku hidup bersih dan sehat (phbs) tatanan rumah tangga di wilayah kerja puskesmas $x$ kota kediri.Jurnal WiyataVol 3, No 1 (2016) diakses dari https://ojs.iik.ac.id/index.php/wiya ta/article/view/66. 